\title{
Immunofluorescence of immunoglobulins and complement in kidneys taken at necropsy
}

\author{
J VARIS, I RANTALA, * A PASTERNACK Departments of Medicine and *Pathology, Tampere \\ University Central Hospital, and Department of Clinical Sciences, University of Tampere, Tampere, Finland
}

SUMMARY The immunofluorescence of immunoglobulins and complement components in kidney specimens taken at necropsy was investigated to determine the persistence of antigenicity of immune reactants. Of 74 consecutive necropsies, 12 cases had positive glomerular fluorescence. The pattern and intensity were followed up for up to 15 days. Along with necropsy specimens, tissue samples of normal looking kidney from 14 nephrectomies were also studied. Two of these specimens turned out to be positive in the immediate immunofluorescence study. To rule out possible false positive staining after death immunofluorescence findings in all nephrectomy specimens were followed up for up to 19 days.

The presence of immunoglobulins and complement could be shown for between 12 and 15 days after death; no changes in immunofluorescence findings occurred during this period. It is concluded that immunofluorescence provides valuable information when immunologically mediated reactions need to be clarified in necropsy kidneys.

While the immunohistochemical demonstration of an immune mediated response is usually confined to the study of fresh tissue samples or properly fixed specimens, for many purposes it would be useful to study samples obtained at necropsy. No data, however, are available on the persistence of antigenicity of immune reactants. Our study aimed at correcting this.

\section{Material and methods}

Kidney specimens were collected from 74 consecutive necropsies kept at $+4^{\circ} \mathrm{C}$. The necropsies had been performed one to nine days after death (table). Small cortical specimens were obtained for immediate light microscopic and immunofluorescence studies. Large cortical speciments were removed and closed in tight plastic bags to prevent them dehydrating at $+4^{\circ} \mathrm{C}$. Twelve cases in which immediate study yielded positive glomerular or vascular immunofluorescence findings for immunoglobulins (IgG, IgA, IgM) or complement components ( $\mathrm{Clq}, \mathrm{C} 3)$, or a combination, were further investigated to evaluate the pattern and intensity of immunofluorescence findings during a

Accepted for publication 12 June 1989 follow up of 10-15 days.

Specimens of normal looking kidney tissue from 14 kidneys removed because of renal carcinoma were followed up for up to 19 days. The specimens were cut from the kidney during surgery by coagulation technique (Diathermia) so that the blood was preserved inside the tissue block obtained. The handling of these specimens was similar to the procedure used for the necropsy specimens

LIGHT AND IMMUNOFLUORESCENCE MICROSCOPY Light microscopy specimens were routinely processed in paraffin wax and the sections stained by haematoxylin and eosin, periodic acid Schiff and Jones' periodic acid-silver methenamine methods. For immunofluorescence, kidney tissue was embedded in Ames OCT compound (Ames Company, Division of Miles Laboratories Inc, Elkhart, Indiana) and frozen in liquid nitrogen. Sections $4 \mu \mathrm{m}$ thick were fixed in absolute acetone at $-20^{\circ} \mathrm{C}$ and stained with fluorescein-isothiocyanate (FITC)-conjugated antisera to human IgG, IgA, IgM, C1 q and C3. Controls included incubation in FITC-conjugated non-specific antiserum and incubation in an unconjugated blocking antiserum prior to use of the FITC-conjugate. All the antisera were obtained from Behringwerke AG (Marburg-Lahn, West Germany). 
Table Immunofluorescence findings of immunoglobulins and complement components in necropsy and nephrectomy specimens durin follow up of 10-19 days

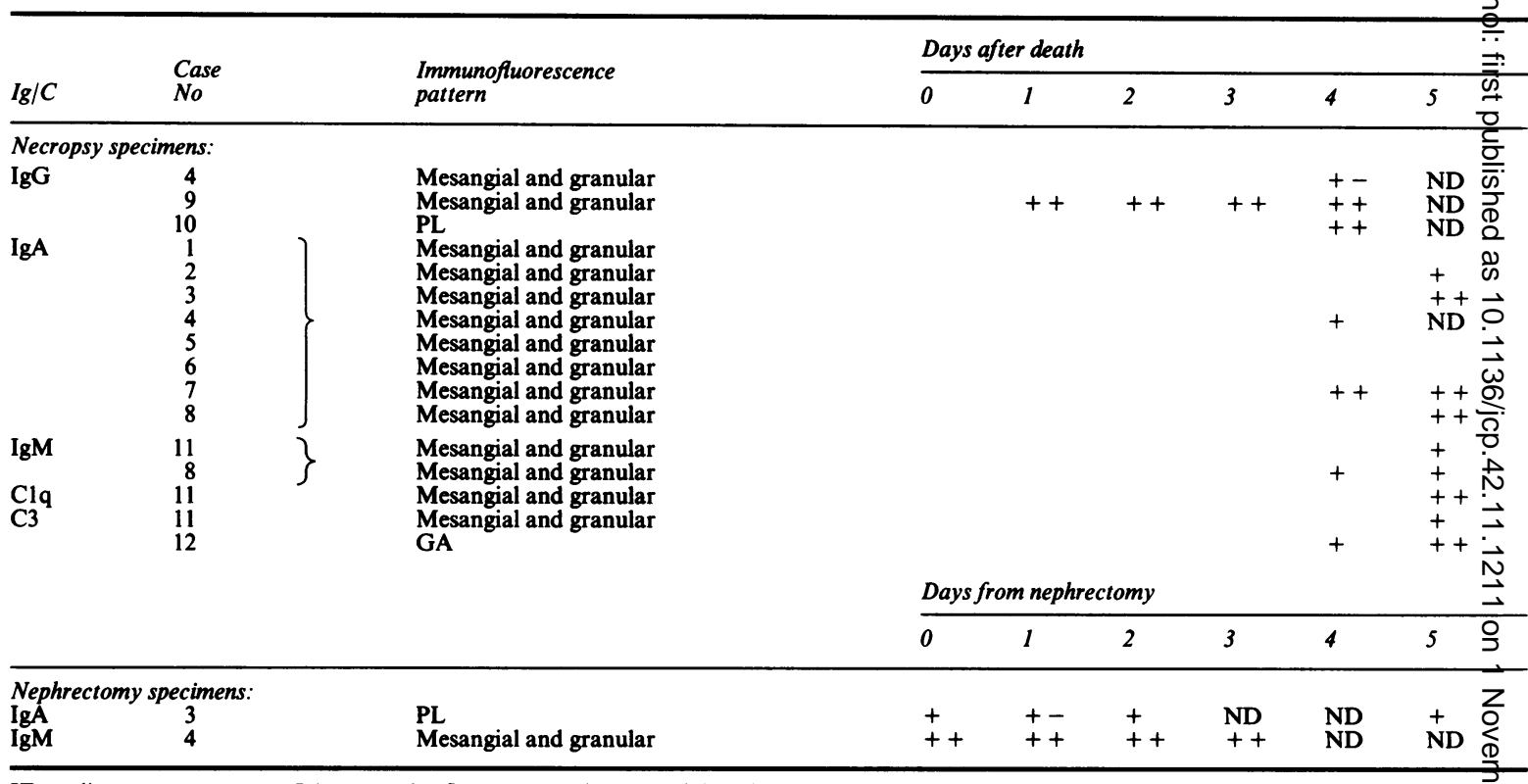

IF grading:,,$+-+++; G A=$ granular fluorescence along arterial walls, PL = pseudolinear fluorescence along glomerular basement membrane $\vec{g}$ nd Bowmann's capsule.

\section{Results}

In the specimens obtained immediately after necropsy there were only slight autolytic light microscopic changes. In 12 immunofluorescence specimens

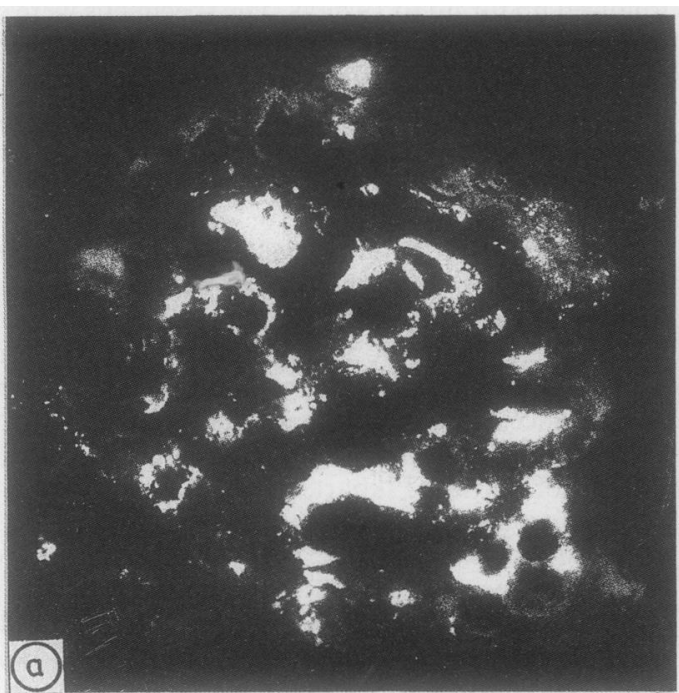

immunoglobulins and complement components were $\stackrel{\overrightarrow{0}}{\circ}$ deposited mesangially and the deposits were granular in appearance (fig 1). Occasionally, C3 was also foundō. in the glomerular hilus. In one diabetic patient? pseudolinear staining for IgG was seen along the

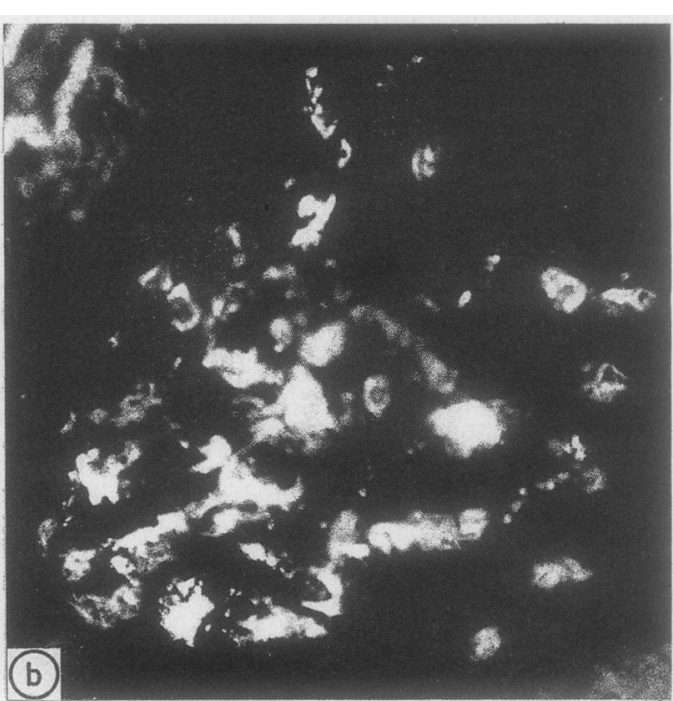

Fig 1 Immunofluorescence staining for IgA showing mesangial fluorescence in case 7, in which necropsy was carried out four days after death. (a) Immunofluorescence staining performed immediately after necropsy; (b) immunofluorescence staining performed 14 days after death. 


\begin{tabular}{|c|c|c|c|c|c|c|c|c|c|}
\hline 6 & 7 & 8 & 9 & 10 & 11 & 12 & 13 & 14 & 15 \\
\hline $\begin{array}{l}\text { ND } \\
\text { ND } \\
\text { ND } \\
+ \\
\text { ND } \\
\text { ND } \\
+ \\
++ \\
++ \\
++\end{array}$ & $\begin{array}{l}+- \\
++ \\
++ \\
+ \\
\text { ND } \\
+ \\
+ \\
++ \\
++ \\
++\end{array}$ & $\begin{array}{l}+- \\
++ \\
++ \\
+ \\
++ \\
+ \\
+ \\
++ \\
++ \\
++\end{array}$ & $\begin{array}{l}+- \\
++ \\
++ \\
++ \\
\text { ND } \\
++ \\
+ \\
+ \\
++ \\
\text { ND } \\
\text { ND }\end{array}$ & $\begin{array}{l}+- \\
++ \\
+ \\
++ \\
\text { ND } \\
++ \\
+ \\
\text { ND } \\
\text { ND } \\
\text { ND } \\
\text { ND }\end{array}$ & $\begin{array}{l}+- \\
++ \\
+- \\
++ \\
+ \\
++ \\
+ \\
\text { ND } \\
\text { ND } \\
++ \\
++\end{array}$ & $\begin{array}{l}++ \\
+ \\
\text { ND } \\
+ \\
\text { ND } \\
++ \\
++\end{array}$ & $\begin{array}{l}\text { ND } \\
\text { ND } \\
\text { ND } \\
+ \\
++ \\
++ \\
++\end{array}$ & $\begin{array}{l}\text { ND } \\
+ \\
++ \\
++ \\
++\end{array}$ & ++ \\
\hline $\begin{array}{l}+ \\
+ \\
++ \\
+ \\
++\end{array}$ & $\begin{array}{l}\text { ND } \\
+ \\
\text { ND } \\
\text { ND } \\
\text { ND }\end{array}$ & $\begin{array}{l}\text { ND } \\
\text { ND } \\
\mathbf{N D} \\
\mathbf{N D} \\
\mathbf{N D}\end{array}$ & $\begin{array}{l}+ \\
\text { ND } \\
++ \\
+ \\
\text { ND }\end{array}$ & $\begin{array}{l}+ \\
+ \\
++ \\
+ \\
++\end{array}$ & $\begin{array}{l}+ \\
+ \\
+ \\
+\end{array}$ & $\begin{array}{l}+ \\
+ \\
+ \\
+\end{array}$ & + & & \\
\hline
\end{tabular}

\begin{tabular}{|c|c|c|c|c|c|c|c|c|c|c|c|c|c|}
\hline 6 & 7 & 8 & 9 & 10 & 11 & 12 & 13 & 14 & 15 & 16 & 17 & 18 & 19 \\
\hline $\begin{array}{l}+ \\
++\end{array}$ & $\begin{array}{l}+ \\
++\end{array}$ & $\begin{array}{l}+ \\
++\end{array}$ & $\begin{array}{l}+ \\
++\end{array}$ & $\begin{array}{l}\text { ND } \\
++\end{array}$ & $\begin{array}{l}\text { ND } \\
\text { ND }\end{array}$ & $\stackrel{+}{\text { ND }}$ & $\begin{array}{l}+ \\
++\end{array}$ & $\begin{array}{l}+ \\
++\end{array}$ & $\begin{array}{l}+ \\
+t\end{array}$ & + & ND & ND & + \\
\hline
\end{tabular}

glomerular basement membranes and Bowmann's capsule.

During the investigation there were no changes in the distribution or intensity of the fluorescence (fig 1). Only the pseudolinear fluorescence for IgG diminished
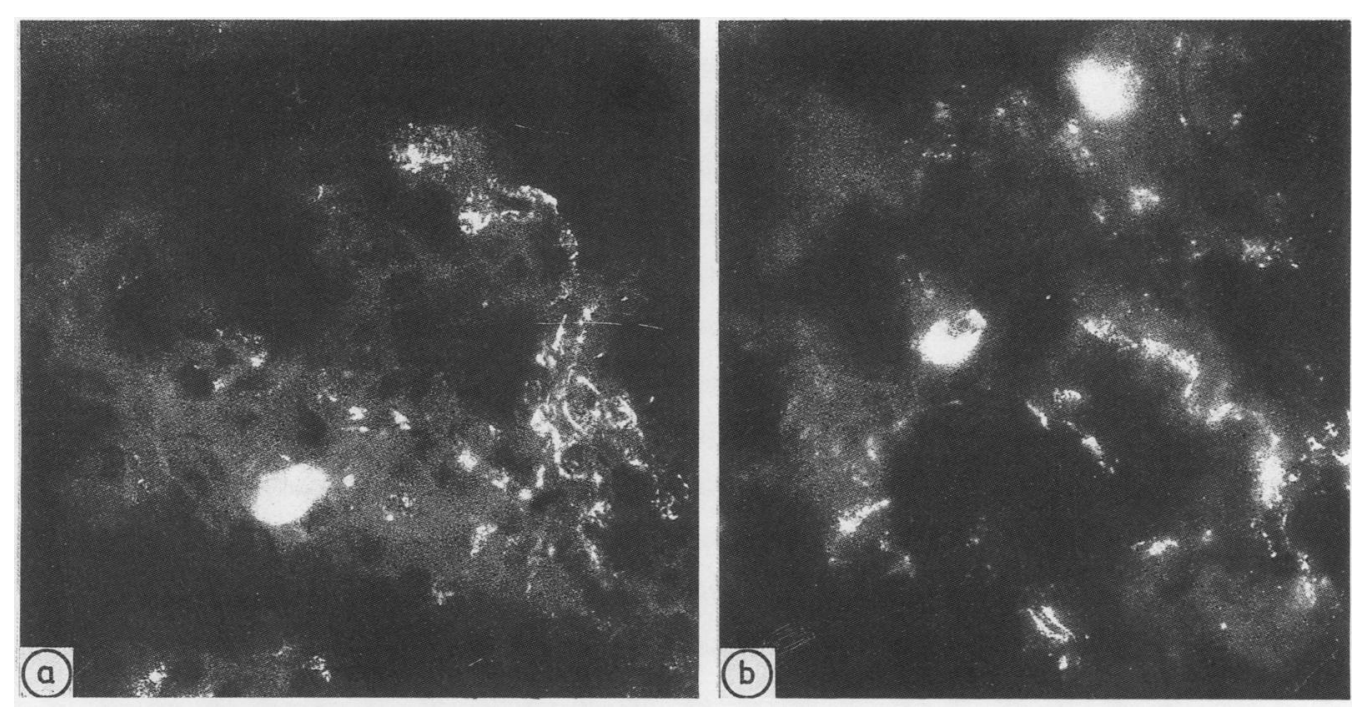

Fig 2 Immunofluorescence staining for IgM showing mesangial fluorescence in case 4. (a) Immunofluorescence staining performed immediately; (b) immunofluorescence staining performed 15 days after nephrectomy.

after nine days. No particular increase occurred in background fluorescence. Although autolysis became evident nine to 10 days after death, it did not hamper interpretation.

The nephrectomy specimens were normal on light 
microscopic examination. One case with mesangial and granular IgM (fig 2) and one case with pseudolinear IgA were found. In both cases the fluorescence intensity remained unchanged during follow up. In the remaining negative specimens no fluorescence appeared for up to 19 days.

\section{Discussion}

In previous studies glomerular immunoglobulins have been shown up to $48^{1}$ and 72 hours $^{2}$ after death. According to Larsen, complement components can be detected with certainty 24 hours after death, after which complement is immunologically changed or destroyed by autolytic processes. ${ }^{3}$ In agreement with these previous studies, ${ }^{1-3}$ we have shown that immune reactants can be shown by immunofluorescence in kidney tissue taken at necropsy. When the effects of autolysis after necropsy were studied, immunoglobulins and complement could be localised up to 12-15 days later. In fact, immunoglobulins remain unchanged for up to 19 days. To prove that immunofluorescence findings in the necropsy material were not due to false positive staining originating from degrading tissue, we repeated the same staining schedule on specimens obtained from nephrectomies. The findings remained unchanged and no immunofluorescence positivity was seen in the 12 originally negative specimens during follow up. Background staining, which, according to Sutherland $e t a{ }^{2}{ }^{2}$ interfered with the interpretation of immunofluorescence, had no harmful effect in our study.

Kidney tissue is rich in hydrolytic enzymes, which makes it vulnerable to autolysis. Nevertheless, immunofluorescence in glomeruli from necropsy tissue provides valuable information on immunologically mediated reactions and is worth adopting when these reactions require clarification.

\section{References}

1 Sinniah R. Occurrence of mesangial IgA and IgM deposits in a control necropsy population. J Clin Pathol 1983;36:276-93.

2 Sutherland J, Van Markham R, Mardiney M. Subclinical immune complexes in the glomeruli of kidneys post mortem. Am J Med 1974;57:536-41.

3 Larsen S. Glomerular immune deposits in kidneys from patients with no clinical or light microscopic evidence of glomerulonephritis. Acta Pathol Microbiol Immunol Scand Sect A 1979;87:313-19.

Requests for reprints to: Dr Juha Varis, Department of Medicine, Tampere University Central Hospital, SF-33520 Tampere, Finland. 